\title{
Interventions among Pregnant Women in the Field of Music Therapy: A Systematic Review
}

\section{Intervenções em gestantes na área da musicoterapia: Uma revisão sistemática}

\author{
Bruna Mayumi Omori Shimada1[ Magda da Silva Oliveira Menezes dos Santos ${ }^{10}$ \\ Mayara Alvares Cabral ${ }^{1}$ Vanessa Oliveira Silva ${ }^{1}$ Gislaine Cristina Vagetti ${ }^{1}$ \\ 1 Universidade Estadual do Paraná (UNESPAR), Curitiba, Paraná, \\ PR, Brazil \\ Address for correspondence Gislaine Cristina Vagetti, Rua dos \\ Funcionários, 1.357, Curitiba, Paraná, PR, 80035-050, Brazil \\ (e-mail: gislainevagetti@hotmail.com).
}

Rev Bras Ginecol Obstet 2021;43(5):403-413.

\begin{abstract}
Objective To investigate in the literature the studies on the benefits of music therapy interventions among pregnant women in the prenatal, delivery and postpartum periods.

Data Sources The search for articles was carried out in the following electronic databases: VHL, LILACS, SciELO, Portal CAPES, PsycINFO, ERIC, PubMed/Medline, and journals specialized in this field: Revista Brasileira de Musicoterapia ("Brazilian Journal of Music Therapy") and Voices.

Study Selection Descriptors in Portuguese (musicoterapia, gravidez, gestantes, revisão), English (music therapy, pregnancy, pregnant women, review) and Spanish (musicoterapia, embarazo, mujeres embarazadas, revisión) were used. The search was delimited between January 2009 and June 2019. The process of selection and evaluation of the articles was performed through peer review.

Data Collection The following data were extracted: article title, year of publication, journal, author(s), database, country and date of collection, purpose of the study, sample size, type of care, intervention, instruments used, results, and conclusion. The data were organized in chronological order based on the year of publication of the study.

Summary of the Data In total, 146 articles were identified, and only 23 studies were included in this systematic review. The articles found indicate among their results relaxation, decreased levels of anxiety, psychosocial stress and depression, decreased pain, increase in the maternal bond, improvement in the quality of sleep, control of the

\section{Keywords}

- pregnancy

- music therapy

- music

- women's health fetal heart rate and maternal blood pressure, and decreased intake of drugs in the postoperative period.

Conclusion Music therapy during the prenatal, delivery and postpartum periods can provide benefits to pregnant women and newborns, thus justifying its importance in this field.
\end{abstract}

received

June 2, 2020

accepted

December 8, 2020
DOI https://doi.org/

10.1055/s-0041-1731924. ISSN $0100-7203$. (c) 2021. Federação Brasileira de Ginecologia e Obstetrícia. All rights reserved.

This is an open access article published by Thieme under the terms of the Creative Commons Attribution License, permitting unrestricted use, distribution, and reproduction so long as the original work is properly cited. (https://creativecommons.org/licenses/by/4.0/)

Thieme Revinter Publicações Ltda., Rua do Matoso 170, Rio de Janeiro, RJ, CEP 20270-135, Brazil 


\section{Resumo}
Palavras-chave
- gravidez
- musicoterapia
- música
- saúde da mulher

Objetivo Investigar na literatura os estudos sobre os benefícios das intervenções musicoterapêuticas em gestantes no pré-natal, parto e pós-parto.

Fontes dos dados A busca dos artigos foi realizada nas seguintes bases de dados eletrônicas: BVS, LILACS, SciELO, Portal CAPES, PsycINFO, ERIC, PubMed/Medline e revistas especializadas da área: Revista Brasileira de Musicoterapia e Voices.

Seleção dos estudos Utilizaram-se descritores em português (musicoterapia, gravidez, gestantes, revisão), em inglês (music therapy, pregnancy, pregnant women, review) e em espanhol (musicoterapia, embarazo, mujeres embarazadas, revisión). A busca foi delimitada de janeiro de 2009 até junho de 2019. Os processos de seleção e avaliação dos artigos foram realizados por revisão por pares.

Coleta de dados Os seguintes dados foram extraídos: título do artigo, ano da publicação, revista, autor(es), base de dados, país e data da coleta, objetivo do estudo, tamanho da amostra, tipo de atendimento, intervenção, instrumentos utilizados, resultados, e conclusão. Os dados foram organizados em ordem cronológica a partir do ano de publicação do estudo.

Síntese dos dados Foram identificados 146 artigos e incluídos apenas 23 estudos na revisão sistemática. Os artigos encontrados indicam em seus resultados relaxamento, diminuição dos níveis de ansiedade, de estresse psicossocial e de depressão, diminuição da dor, aumento do vínculo materno, melhora da qualidade do sono, controle da frequência cardíaca fetal e da pressão arterial materna, e diminuição da ingestão de fármacos no pós-operatório.

Conclusões A musicoterapia durante o pré-natal, parto e pós-parto pode trazer benefícios para a gestante e para o neonato, o que justifica sua importância nessa área.

\section{Introduction}

Pregnancy is a period characterized by physical, hormonal and emotional changes. ${ }^{1}$ The birth marks a new phase in the life of the woman, the puerperium, which ends when the woman's body returns to the stage previous to pregnancy. ${ }^{2}$

Pregnant women are especially affected by stress during pregnancy, childbirth and the postpartum period. Several art forms have been studied in order to evaluate their relaxing potential and their effects on the physiology of individuals. Music has been a constant target of research regarding its effects on the most diverse groups of patients. The existing data point to its importance in improving the concentration, attention and physical endurance of the patients. ${ }^{3}$ And it has been shown to be beneficial in the emotional, intellectual, psychological, physiological and social fields, ${ }^{4}$ in addition to having specific beneficial effects regarding depression and normal postpartum pain, anxiety and greater satisfaction in the postpartum period. ${ }^{5}$

In pregnant women, these effects can be explained by a series of physiological mechanisms that are activated at the moment of listening to music, which remain activated for a prolonged period. As the main neurotransmitters related to music therapy, natural serotonin - which creates a state of relaxation - and acetylcholine have their potential boosted, with an effect of reducing the heart rate and blood pressure, and increasing blood flow to noble organs. ${ }^{6}$ Listening to music also causes the glucocorticoids such as cortisol, which are strongly related to the state of stress, to have a reduced release, with a consequent benefit regarding fetal development, since they are able to cross the placental barrier and directly interfere in fetal physiology. ${ }^{7}$

A form of treatment that aims at the physical, mental and psychological integration of the patient, music therapy is also one of the methods used as a support in pregnancy. Some studies in the literature have shown that musical interventions have an insignificant effect on the reduction in stress during pregnancy $^{8}$ and in the decrease in pain during childbirth. ${ }^{9}$ However, there a significant improvement in the levels of anxiety during pregnancy and labor has been observed. ${ }^{8,9}$ A systematic review by Van Willenswaard et al..$^{8}$ points out that no study on music therapy was found during their detailed search, diverging from other systematic reviews that examined interventions made by a music therapist. In view of the divergent results in the literature, the importance of the present study is evident. Therefore, the aim of the current study was to investigate in the literature about the benefits of music therapy interventions among pregnant women in the prenatal, delivery and postpartum periods.

\section{Methods}

\section{Type of study}

The present is a systematic literature review performed according to the Preferred Reporting Items for Systematic Reviews and Meta-Analyses (PRISMA) statement. ${ }^{10}$ The 
methodology of a systematic review has a high performance in identifying scientific evidence. According to the Oxford Center for Evidence-Based Medicine (OCEBM), ${ }^{11}$ the typology of the systematic review is classified as level 1 out of 5 possible levels in the representation of evidence, as it makes it possible to establish a panorama on the studied topic. We used the The State of the Art through Systematic Review (StArt) software, developed by the Software Engineering Research Laboratory (Laboratório de Pesquisa em Engenharia de Software, LAPES, in Portuguese) of Universidade

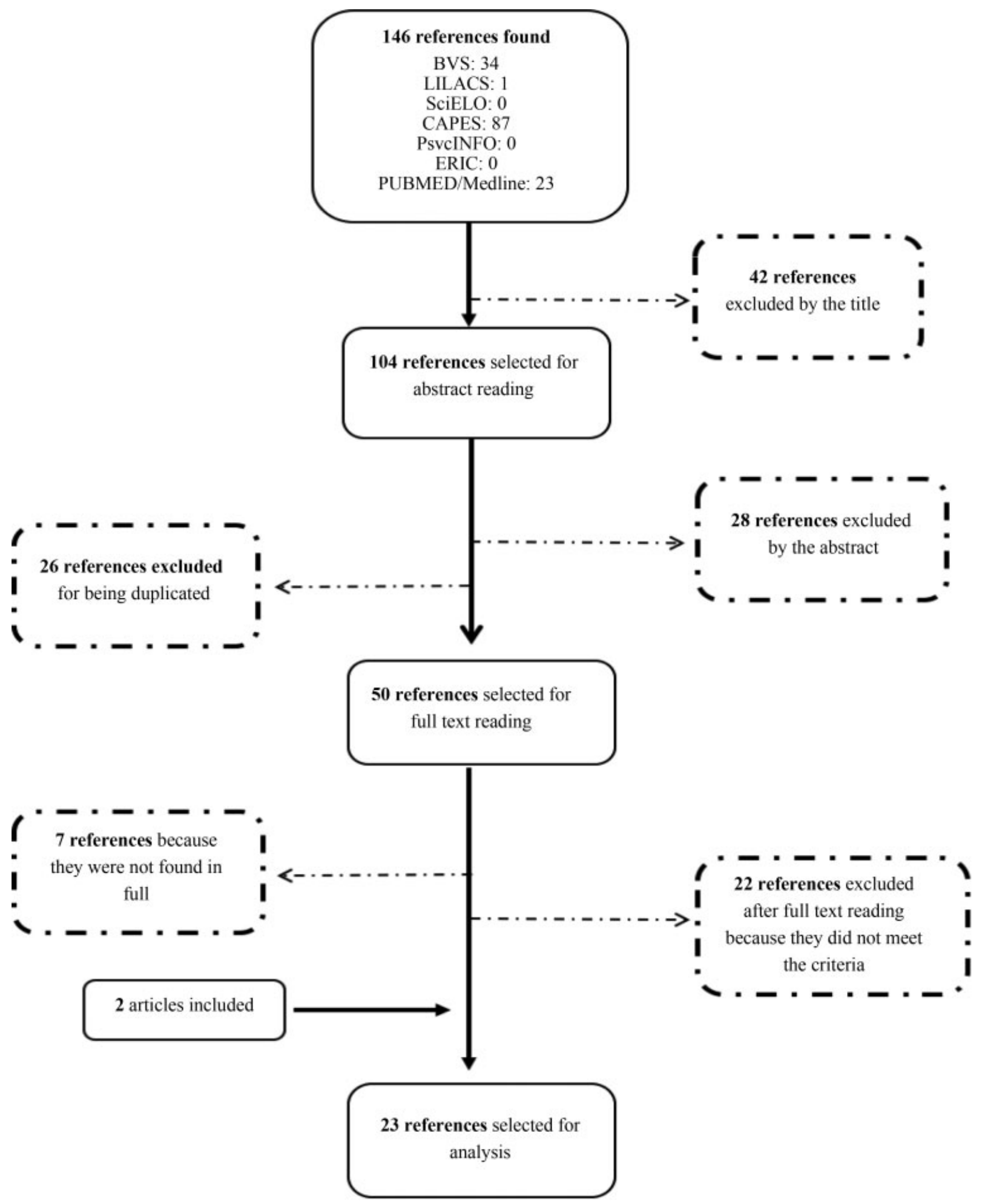

Fig. 1. Flowchart of the process of search and selection of studies. 
Federal de São Carlos, Brazil, which supports the researcher in the systematic review.

\section{Search strategy}

The research question was formulated using the "PICO" framework, which means population (participants), intervention (or exposure, for observational studies), comparison, and "outcome", with some researchers preferring to add and "S" (for study design), therefore naming it PICOS. ${ }^{12}$

The search was carried out in the following electronic databases: Biblioteca Virtual de Saúde (BVS), Literatura Latino-Americana e do Caribe em Ciências da Saúde (LILACS), Scientific Eletronic Library Online (SciELO), Portal CAPES, PsycINFO, Education Resources Information Center (ERIC), PubMed/Medline, and in journals specialized in the field: Revista Brasileira de Musicoterapia ("Brazilian Journal of Music Therapy") and Voices.

It was delimited from January 2009 to June 2019, considering articles published in Portuguese, English and Spanish. We used descriptors in Health Sciences (DeCS), Medical Subject Headings (MeSH) and Thesaurus in Portuguese (musicoterapia, gravidez, gestantes, revisão), in English (music therapy, pregnancy, pregnant women, review) and in Spanish (musicoterapia, embarazo, mujeres embarazadas, revisión). Descriptors were combined using the Boolean operators "AND" and "OR".

The articles were selected and evaluated by peer review and organized in phases: in the first phase, an initial analysis of the titles of the manuscripts was carried out; in the second phase, an evaluation of the abstracts was performed. In the third phase, all selected articles were obtained in full, and were subsequently examined according to the established inclusion and exclusion criteria.

\section{Inclusion and exclusion criteria}

The inclusion criteria were: original articles published in journals; and studies published from January 2009 until June 2019. The exclusion criteria were: theses, dissertations, monographs and studies that did not reach a minimum score of 18 points in the Downs and Black ${ }^{13}$ checklist. If differences occurred during the review of the articles, new discussions were held until both reviewers agreed with the review.

\section{Data extraction}

The following data were extracted from the articles included: title, year of publication, journal, author(s), database, country and date of collection, objective of the study, sample size, type of care, intervention, instruments used, results, and conclusion. The articles were organized in chronological order based on the year of publication.

\section{Results}

-Figure 1 presents a flowchart of the search and selection process. In the analysis of the titles, 104 studies were selected and had their abstracts read; 50 studies were considered relevant, and their full texts were read. Out of these studies, 22 were excluded because they did not meet the eligibility criteria, and 7 references were excluded because they were not found in full. During the search, we included two articles found in the references of other articles. The electronic search generated 23 studies, with 8 articles on childbirth and postpartum, and 15 studies related to prenatal care (-Figure 1).

\section{Discussion}

Regarding the studies selected ( - Table 1), 6 were from Turkey, and they reported decreased anxiety, FCF, PA, and postoperative pain; ${ }^{5,14-18} 3$ were from Brazil, with results regarding the reduction of pain;1,19,20 3 were from Taiwan, and they reported decreased stress and anxiety, improved quality of sleep, and decreased pain in the initial phase of labor ${ }^{21-23} ; 3$ were from Spain, with results describing decreased anxiety, PAS, PAD and HR and fetal reactivity ${ }^{4,24} ; 1$ was from Ireland, and the researchers achieved relaxation and increased bonding; ${ }^{25} 1$ was from the United Kingdom, and it reported decreased anxiety and prenatal depression; ${ }^{26} 1$ ws from China, and the researchers found decreased anxiety and physiological responses. $^{27} 1$ was from the United States, reporting reduced suffering before delivery ${ }^{28} ; 1$ was from India, and the researchers obtained fetal stimulation; ${ }^{29} 1$ was from South Korea, reporting decreased anxiety and $\mathrm{FCF}^{30} ; 1$ was from Israel, reporting an increase in positive emotions and a decrease in negative emotions; $;^{31}$ and 1 was from Iran, reporting lower pain scores. $^{32}$

The articles regarding the prenatal period, delivery, and the postpartum period report relaxation, decreased levels of anxiety, psychosocial stress, depression and pain, increased maternal bond with the baby, improved quality of sleep, control of fetal heart rate and maternal blood pressure, and decreased drug intake in the postoperative period. According to Carvalho, ${ }^{33}$ music stimulates action and emotional expression in individuals, and prompts them to control states of physical and psychological homeostasis, having effects on physiology, behavior, cognition, emotions, and social interaction. $^{33}$

Regarding the prenatal period, 15 articles were analyzed, and 9 of them were relevant for the present review, for they dealt with anxiety in parturient women, and 4 out of these 9 studies were carried out during the nonstress test. According to Primo and Amorim, ${ }^{34}$ during pregnancy women may experience anguish and anxiety due to the need to adapt to situations regarding maternity.

As for childbirth, seven articles were analyzed; four of them were related to pain during labor, six dealt with anxiety, and two reported a significant reduction in blood pressure. In the study by Gayeski and Brüggemann, ${ }^{35}$ the perception of mothers regarding non-pharmacological methods for pain relief, the feeling of well-being, an having emotional support were reported to facilitate the parturition process. The authors state that there is a need to expand information on these methods throughout pregnancy, and they point out that there are more investigative studies on the use of these non-pharmacological methods for pain relief in women in labor, which aim to improve humanized actions 
Table 1 Summary of the articles selected for the systematic review

\begin{tabular}{|c|c|c|}
\hline Title, author, year & Objective & $\begin{array}{l}\text { Country, } \\
\text { year of collecti } \\
\text { and sample siz }\end{array}$ \\
\hline \multicolumn{3}{|l|}{ PRENATAL PERIOD } \\
\hline $\begin{array}{l}\text { Music therapy to } \\
\text { relieve anxiety in } \\
\text { pregnant women on } \\
\text { bedrest: a random- } \\
\text { ized, controlled trial; } \\
\text { Yang et al. (2009) }\end{array}$ & $\begin{array}{l}\text { To explore the effect } \\
\text { of music therapy on } \\
\text { anxiety relief for } \\
\text { pregnant women on } \\
\text { bedrest }\end{array}$ & $\begin{array}{l}\text { China; } 2007 \\
120 \text { pregnant } \\
\text { women }\end{array}$ \\
\hline
\end{tabular}

Alleviating distress To examine the ef- USA/2009 61 during antepartum fectiveness of a sin- pregnant women hospitalization: a ran- gle music session or domized controlled intervention with trial of music and re- recreation therapy creation therapy; to reduce anteparBauer et al. $(2010)^{28}$ tum-related suffering among women with high-risk pregnancies who experience prolonged antepartum hospitalizations

Novel method of feto- To monitor fetal maternal monitoring movements with using music therapy - a and without music non-stress test; Kumar et al. $(2011)^{29}$
India; 2010; 9 pregnant women

.

.

$\begin{array}{llll}\text { Type of care and intervention Instruments used Results } & \text { Conclusion }\end{array}$

Group care Duration: 3 consecu- State-Trait Anxiety tive days. Description: the preg- Inventory nant women in the experimental group received music therapy for 30 minutes on 3 consecutive days. Pregnant women who received routine care had a 30 minute rest on 3 consecutive days. The variables included anxiety and physiological responses

Individual care. Duration: before Antepartum Bedrest and after, within 48 to 72 hours Emotional Impact after delivery. Description: Inventory randomized, single-blinded study; participants received

1 hour of music or recreational therapy, or were placed in an attention control group. Suffering related to

antepartum was measured by the Emotional Impact Inventory of Antepartum Rest, which was administered before and after the intervention and in a followup

period of between 48 and 72 hours

Individual care. Duration: not mentioned. Description: the music was set to be heard on a walkman and, the headphones were placed around the pregnant woman's

abdomen. The volume of the music was kept at a moderate level of no more than 70 decibels. Fetal movements were measured by pressure sensors. The voltages obtained with and without music were amplified by the AD620 and fed to the NI 6015 for the purpose of monitoring and storage on the PC with a sampling time of 200 ms using the Labview environment

Effect of maternal To investigate the Turkey; 2009; Group and individual care Dura- State-Trait Anxiety anxiety and music on effect of the non- 201 pregnant women. tion: not mentioned. Description: Inventory fetal movements and stress test and music Group with music fetal heart rate pat- $\quad$ on maternal anxiety $=96$; group without terns; Kafali et al. and the effect of music $=105$ $(2011)^{14}$ maternal anxiety and music on fetal pregnant women who came for routine prenatal care were randomized to receive music $(n=96)$ or no music $(n=105)$ during the non-stress test. Before and after the test, these women were asked to complete the Spielberg State-Trait Anxiety Inventory in two interviews; the primary outcome was considered maternal state anxiety scores before and

after the non-stress test. The secondary outcome was the baseline fetal heart rate, the number of fetal movements, major accelerations, dubious non-stress test, variable decelerations, and the minimum procedure time.

The Limerick Lullaby To explore the im- Ireland; 2009; 6 pregproject: an interven- pact of lullaby sing- nant women tion to relieve prenatal ing during stress; $\quad$ pregnancy Carolan et al. $(2012)^{25}$

Group care. Duration: 4 sessions. Questionnaire with Description: the pregnant wom- open questions en were recruited in childbirth classes at a maternity hospital. Six pregnant women participated and learned to sing three lullabies in four group sessions with musicians. In-depth qualitative views were taken approximately three months later to capture the experiences of the women.
Anxiety levels decreased and physiological responses imed according to the ine gregnant woman is an music therapy during bedrest inexpensive and effective method to reduce anxiety in women with high-risk pregnancies and who are on bedrest

Significant associations were Music interventions in found between the provision of a single recreational music and recreational therapy therapy session and the reduction of suffering effectively alleviate related to the antepartum in antepartum-related women hospitalized with high- suffering among highrisk pregnancies. These statisti- risk women who uncally significant reductions in dergo suffering persisted over a period hospitalization before of 48 to 72 hours delivery, and should be considered as a complement to any comprehensive antepartum program
Not mentioned

With music, it increased from Music can serve as a $146 \mathrm{bpm}$ to $169 \mathrm{bpm}$. The test is means of communicareactive if there is a minimum tion with the fetus 10-15 bpm increase in normal through sounds and heart rate during fetal move- voices. Caressing the ments, otherwise the test is not fetus through the belreactive. This state was also ly, producing soft and verified by ultrasound. This test melodic sounds, using is reactive and good for the lights and vibrations health of the fetus the baby: these stimuli are in an organized and pleasant pattern

Before the non-stress test, the The non-stress test has average state-trait anxiety anxiogenic effects on scores of the music and control mothers and listening groups were of $38.1 \pm 8.8$ and to music, and a posi$38.08+8.2$ respectively. On the tive impact on materother hand, after the non-stress nal and fetal test, the average state-trait parameters, but it is an anxiety scores of the music and open question whethcontrol groups were of er maternal anxiety $35.5+8.2$ and $40.2+9.2$ during pregnancy can respectively. While in the control affect fetal acceleragroup the non-stress trest tions to the point of brought about a statistically influencing clinical significant increase in the state- judgment trait anxiety scores, listening to music during the non-stress test resulted in a decrease in statetrait of anxiety scores in the study group; however it was not statistically significant. The baseline fetal heart rate of the music group was significantly higher than that of the control group

They suggest that learning to The main advantage of sing lullabies during pregnancy this intervention is has benefited women in terms of that it is non-pharmarelaxation, feeling closer to the cological and easy to fetus, connecting with other implement. At the pregnant women, and providing same time, it appears an additional tool for communi- to be a pleasurable cation at the beginning of the exercise for pregnant newborn period. Some women women, and it has an described a deep feeling of love effect on reducing maternal stress and 
Table 1 (Continued) apy on parturient anx- fectiveness of music women; study group anxiety during the group $=14$ first clinical period of childbirth using the methodology of clinical, controlled and randomized

teaching

The effects of music To examine the listening on psychoso- effects of listening nal-fetal attachment social stress and during pregnancy maternal-fetal atChang et al. (2015) ${ }^{21}$ tachment during pregnancy
Effects of music ther- To evaluate the ef- Brazil; 29 pregnant iety; Lima et al. (2014) therapy in reducing $=15$; control cial stress and mater- to music on psycho-
Taiwan; 2009-2010; Individual care. Duration: 296 pregnant women; 30 minutes for 2 weeks. Destudy group $=145$; control group $=151$ scription: the study group relistened to music. The control group received only routine prenatal care Stress Scale; and Ma- level of psychosocial stress in the listening to music in

and connection with the fetus encouraging infant while singing the lullabies attachment

Care was not mentioned. dura- State-Trait Anxiety tion: not mentioned. description: Inventory not mentioned.

All pregnant women in the study When submitted to group reported that undergoing the intervention with music therapy was easy, and that music therapy, there they would use music therapy in was a reduction of the next labor. After the inter- anxiety in 3 patients in vention, the researchers ob- the study group. The served a decrese in the grade of parturients in the anxiety from high to medium in control group main2 patients, and from high to low tained the degree of in 1 patient anxiety throughout delivery

Pregnancy Stress Rat- The results of the posttest The findings support ing Scale; Perceived identified a significantly lower the effectiveness of ternal Fetal Attach- study group compared with the helping pregnant controls, particularly regarding women cope with the stresses related to baby care, stress, especially the change in family relation- pregnancy-related ships, and the identification of stress. Although this
Individual care. Duration: 30 minutes for 2 weeks. Deity Index, Perceived fo statistically significant difscription: the control group re- Stress Scale, and State- the 60 pregnant women with ceived only the usual prenatal Trait Anxiety Inventory sleeping disorders in their decare. The study group was instructed to listen to at least 1 record (30 minutes) of the five pre-recorded CDs compiled by the researcher, or a minimum of 30 minutes of their favorite music per day at bedtime for two weeks mographic and clinical characteristics or the scores on the scales prior to the administraanalysis confirmed that the posttest scores on the scales from their initial scores. With all
State-Trait Anxiety

Individual care. Duration: 20 minutes; the number of days Inventory

was not mentioned. Description: the prepared songs had a time of 60 to 80 beats, and were based on the pregnant woman's heart count. The songs were divided into 5 genres, such as hymns or contemporary Christian music, classics, pop, and, with the help of music experts, a total of 25 CDs were made ( 5 songs of each genre). The isolated space was used to block out the noise. In the study group, after the non-stress test, the State-Trait Anxiety Inventory was applied, blood pressure, pulse and temperature were recorded, while the songs selected by the pregnant woman were played for 20 minutes. In the control group, the non-stress test was applied, but there was no music while collecting the data
Effects of prenatal music stimulation on state/trait anxiety in and its influence onchildbirth: a full-term pregnancy
To investigate the effect of in maternal anxiety, before and after th non-stress test, and
Spain; 2013-2014; 409 Individual care. Duration: pregnant women; study group $=204$; control group $=205$ to music for 14 sessions, three times a week, at the same time of day. Description: the 409 pregnant women who went for 40 minutes per session; listening Inventory the maternal role scales prior to the administra-
tion of musical intervention. The reflected significant differences other variables controlled, the women in the study group had statistically lower scores on the scales than the controls

study found no effect on musical hearing on perceived general life stress or maternal-fetal attachment, the evidence indicates that music is an effective non-invasive pregnancy-related inwhich has minimal or no side effects and is economical and convenient

This study pointed out that two-week musiccan reduce stress, anxiety and improve the quality of sleep of pregnant women with sleeping disorders. The analysis of participants' diaries also suggested that mothers' choices about musical genres may be more correlated with perceived prenatal benefits or with the desire to interact with the fetus

The study group had signifi- Musical intervention cantly lower scores on the anxi- can be effective for ety scale than the controls. anxiety during the

There were no significant differ- non-stress test ences in systolic blood pressure and pulse rate between the two groups. The baseline fetal heart rate was significantly lower in the study group than in the controls. Acceleration frequency in fetal heart rate was significantly increased in the study group compared to the controls. There were no significant differences in fetal movement and test time for reactive non-stress test between the groups tervention for women listening interventions
State-Trait Anxiety

s.




$\begin{array}{ll}\text { randomized con- } & \text { the effect of music } \\ \text { trolled trial; García } & \text { on delivery } \\ \text { González et al. (2018) } & \end{array}$

González et al. (2018) routine prenatal care were ran-

domized in the third trimester to

receive music $(n=204)$ or no

music $(n=205)$ stimulation dur-

ing the non-stress test. The study

group intervention were in-

formed about how to listen to the

music at home and received

music recorded on $\mathrm{CDs}$ score score of each group was stress test and

recorded; study group: improves the delivery

$30.58 \pm 13.2$; control group: process by reducing

$43.11(p<0.001)$ the first stage of labor
Effects of prenatal To identify the Spain; 2013-2014; 409 Individual care. Duration: music stimulation on effects of prenatal pregnant women; fetal cardiac state, musical stimulation study group $=204$; newborn anthropo- $\quad$ on the vital signs of control group $=205$ metric measurements pregnant women at and vital signs of term, on the modifipregnant women: A cation of the fetal randomized con- cardiac state during trolled trial; García the fetal monitoring González et al. (2017) ${ }^{4}$ cardiotocograph and on the anthropometric measurements of newborns after birth to music for 14 sessions, 3 tine prenatal care were
40 minutes per session; listenin times a week, at the same time day. Description: The 409 pregnant women who went for rou-

randomized in the third trimester to receive music $(\mathrm{n}=204)$ or no music $(n=205)$ stimulation during the non-stress test. The study group were informed about how to listen to the music at home and received music recorded on CD Effect of Turkish clas- To evaluate the ef- Turkey; 2012-2014; 70 sical music on prenatal fect of music thera- pregnant women; anxiety and satisfac- $\quad$ py on anxiety and study group $=35$; tion: a randomized satisfaction in preg- control group $=35$ controlled trial in nant women with pregnant women with pre-eclampsia pre-eclampsia; Toker and Kömürcü (2017) ${ }^{15}$

Individual care. Duration:
Fetal cardiac status, The graphs showed a significant Music can be used as a maternal vital signs, increase in FCFB and greater fe- tool that improves the anthropometric meas- tal reactivity, with accelerations vital signs of pregnant urements of the fetus of fetal heart rate in pregnant women during the women with musical stimula- third trimester, and tion. After the fetal monitoring can influence the fecardiotocograph, there was a tus, increasing fetal statistically significant decrease heart rate and fetal in systolic and diastolic blood reactivity Pressure and heart rate in women in the study group
Personal Information The differences in anxiety scores It can be suggested 30 minutes, every day, for 7 days. Form, State-Trait Anxi- were not statistically significant that nurses and midDescription: the pregnant wom- ety Inventory, systolic $(p>0.05)$. On the other hand, wives can use music en in the study group were sub- and diastolic blood the Newcastle Satisfaction therapy in the care and jected to a 30-minute classical pressure, pulse and scores of the study group were monitoring of pregTurkish music session every day respiratory rate, non- higher than those of the controls nant women with prefor a period of 7 days ( 5 days stress test, fetal $\quad(p<0.01)$. Finally, when consid- eclampsia in obstetric before and 2 days after delivery) movements, fetal ering fetal movement counts, a units while the controls received rou- heart rate (for the first significant increase was detertine care and were also assigned 5 days) 30 minutes bedrest per day

Prenatal singing sound alchemy for pregnant women; Martins (2017) ness of women's body wisdom, empowerment, expression of the pregnant woman's feelings, affective communication between the pregnant woman and the baby in the womb
Brazil; 2016; 12 preg- Group care. Duration: weekly, 2 hours long. Description: the methodology of the prenatal singing classes involved female songs and games of musical and vocal improvisation; sound meditations with creative visualizations; sound bath; circle singing; body breathing; and vocal exercises to prepare for childbirth; and sound improvisations with musical instruments
Not mentioned
Vocal exercises were keys that opened the doors for connection with the nature of the female body. They had as objectives to release the voice and to express sensations and feelings vocally to unveil the relations among the voice, the pelvic floor and breathing, and to send affective sonic vibrations to the fetus in the womb. The experiences emphasized the affective dimension in the act of singing: the vibrational communication that the pregnant woman established in the communication with her unborn child

Individual care. Duration: 20 minutes, for 12 weeks. Description: the study group listened to specially-composed songs daily, and the control group did daily relaxation. Composer Jennie Muskett wrote the songs specifically for use during pregnancy. The songs were composed using specific times, musical forms and phrases designed to induce a calm state toms of anxiety and music would be an depression: a pilot effective intervenstudy; Nwebube et al. tion to reduce $(2017)^{26} \quad$ symptoms of prenatal anxiety and depression
State-trait anxiety lev- To investigate the els during pregnancy effect of music therand fetal parameters apy on maternal with music therapy; after the non-stress

Garcia-Gonzalez et al. test, and the effect $(2018)^{7}$ of maternal anxiety
on the process of childbirth and birth
Spain; 2013-2014; 409 Individual care. Duration:
pregnant women; 40 minutes per session; liste study group $=204$ to music for 14 sessions, 3 times a week, at the same time of day. Description: the 409 pregnant women who went for routine prenatal care were randomized in the third trimester to receive music $(n=204)$ or no music $(n=205)$ stimulation during the non-stress test. The study
State-Trait Anxiety In- The study group showed lower Although this pilot ventory, Edinburgh values of trait anxiety study showed high Postnatal Depression $\quad(p=0.0001)$ (effect size: 0.80$)$, levels of friction, the Scale state anxiety $(p=0.02)$ (effect results suggest that size: 0.64) and Edinburgh Post- listening to relaxing natal Depression Scale music regularly should $(p=0.002)$ at week 12 in rela- be further explored as tion to the baseline by the paired an effective non-phar$t$-test. There were no such macological means to changes in the control group reduce anxiety and prenatal depression

After the non-stress test, the The intervention of study group had significantly music therapy during lower scores on state anxiety as pregnancy can reduce well as trait anxiety than the high levels of trait controls. In addition, the study anxiety during the group had lower levels of trait third trimester. Furanxiety than the controls in re- ther research on the lation to the variables of the influence of music birth process, and greater therapy as an interweight at birth and breast vention on maternal anxiety and on the 
410 Interventions among Pregnant Women in the Field of Music Therapy Shimada et al.

Table 1 (Continued)

group were informed about how to listen to the music at home and receive music recorded on CDs

\section{DELIVERY}

Effect of music on la- To verify and de- Brazil; 2008; initially, Group care. Duration: from pre- Not mentioned bor and on the new- scribe the effects of 87 pregnant women, natal care to the postpartum pe-

born; music in the labor of but only 27 fulfilled

Tabarro et al. (2010) ${ }^{20}$ women assisted in the criteria for five maternities; to inclusion verify the baby's behavior and reactions, when submitted to the melodies listened to by their mothers during pregnancy and labor, through the mothers' speeches, obtained in the first three months after delivery

Effects of music ther- To investigate the Taiwan; 2009; 60 apy on labor pain and effects of music on pregnant women; first-time mothers; Liu and anxiety during control group $=30$ et al. $(2010)^{23}$ labor

riod. Description: musical

awareness through a portable tape player, a series of 8 to 10 melodies was made available, selected especially for the study, in an intensity compatible with the acceptance of the group. The period for this experiment ranged from 35 to 45 minutes. In each session, a different series of melodies was listened to by the same group. The groups ranged from two to nine women. The information recorded on the sheets of each pregnant woman alized CD that was then delivered to each future mother with the recommendation to take it to the maternity ward at the time of delivery. During the time of observation of labor, every 2 hours, the music was suppressed for a period of 30 minutes. At the end of each of these periods, the elements of control of the evolution of labor were recorded on an observation sheet received only routine care. A vi- ety and Finger anxiety in Taiwanese the reaction to pain study group $=30$; was used to record an individu-

Individual care. Duration: during Visual Analog Scale for In comparison with the controls, This study provides delivery. Description: the study Pain, Present Behav- the study group presented sig- evidence for the use of group received routine care and ioral Intensity, Visual nificantly lower pain, anxiety and music as an intervenmusic therapy, while the controls Analog Scale for Anxi- finger temperature during the tion for pregnant sual analog self-report scale for Temperature pain and a nurse assessed the behavioral intensity present to measure labor pain. Anxiety was measured with a visual analog scale for anxiety and finger temperature. Pain and anxiety between groups were compared during the latent phase $(2-4 \mathrm{~cm}$ of cervical dilation) and active phase $(5-7 \mathrm{~cm})$ separately

Comparison between To compare the massage and music effects of massage therapies to relieve the and music therapy severity of labor pain; on the severity of Taghinejad et al. labor pain $(2010)^{32}$

Effect of music on la- To evaluate the ef- Turkey; 2012; 156 bor pain relief, anxiety fect of music on la- pregnant women; level and postpartum bor pain and anxiety, study group $=77$; analgesic maternal control group $=79$
Iran; 2007; 101 preg- Individual care. Duration: during Visual Analog Scale nant women; massage the latent phase of labor. Degroup $=51$; music therapy group $=50$ randomly divided into two groups. Pain was measured using the visual analog scale, and the two groups were compared in terms of pain intensity before and after the interventions. As soon as the cervix was dilated by up to $3-4 \mathrm{~cm}$, women in the massage therapy group were asked to close their eyes and breathe rhythmically and deeply During contractions of the uterus, they were asked to breathe more deeply and more calmly, concentrating on the massage. All patients in this group received a 30-minute massage. The women in the music therapy group were asked to listen to soft traditional music ( 1 of 5 optional types) without lyrics, using headphones for 30 minutes, starting early in the active phase of labor

Individual care. Duration: during Visual Analog Scale labor. Description: the study

group listened to music during

labor. Pain intensity and anxiety scription: pregnant women hospitalized for normal delivery were of music on the newborns, 20 the parturient in the form the observation with her no significant and anxiety durfound between the two groups ing the latent phase of in any of the outcome measures labor. The results conduring the active phase firm that listening to music is an acceptable and non-medical coping strategy for pregnant women, especially for the reduction of pain and anxiety in the initial phase of labor

Mothers in the massage therapy Massage therapy has group had a lower level of pain proven to be an effeccompared to those in the music tive method for reduc therapy group $(p=0.009)$. A ing and relieving labor significant difference was ob- pain compared to muserved between the two groups sic therapy, and can be in terms of severity of pain after clinically recomthe intervention $(p=0.01)$. La- mended as an alternabor pain was significantly re- tive. It is a safe and lieved after therapeutic massage affordable method of $(p=0.001)$ pain relief, in which the use of pharmacological or non-pharmacological methods are optional level of pain and anxiety com pared to the controls at all stages of labor. A significant
The study group had a lower
Listening to music during labor has a positive impact on labor pain and anxiety, circumference in the newborn, birth process and birth respectively size are needed during pregnancy

Only 12 parturients had their Effects such as pain labor accompanied by the mel- relief during contracodies of their choice, and they tions, help in reducing were interviewed in the post- tension and fear, envpartum period. As for the effect ronmentalization of mothers were interviewed; 1 of hospital, encouragethe 12 accompanied in labor did ment to prayer and not have her stereo during the spirituality have been puerperium, and could not per- reported. baby 
Table 1 (Continued)

\begin{tabular}{|c|c|c|c|}
\hline $\begin{array}{l}\text { requirement: a ran- } \\
\text { domized controlled } \\
\text { clinical trial; Simavli } \\
\text { et al. }(2014)^{16}\end{array}$ & $\begin{array}{l}\text { hemodynamics, fe- } \\
\text { tal-neonatal param- } \\
\text { eters, and the need } \\
\text { for analgesics in the } \\
\text { postpartum period } \\
\text { in pregnant women }\end{array}$ & & $\begin{array}{l}\text { levels were measured using the } \\
\text { Visual Analog Scale. The two } \\
\text { groups were compared in terms } \\
\text { of pain severity, anxiety level, } \\
\text { maternal hemodynamics, fetal- } \\
\text { neonatal parameters, and need } \\
\text { for analgesics in the postpartum } \\
\text { period }\end{array}$ \\
\hline $\begin{array}{l}\text { Effect of music thera- } \\
\text { py during vaginal de- } \\
\text { livery on postpartum } \\
\text { pain relief and mental } \\
\text { health; Simavli et al. } \\
(2014)^{5}\end{array}$ & $\begin{array}{l}\text { To evaluate the } \\
\text { effects of music } \\
\text { therapy on postpar- } \\
\text { tum pain, anxiety } \\
\text { level, satisfaction, } \\
\text { and rate of early } \\
\text { postpartum } \\
\text { depression }\end{array}$ & $\begin{array}{l}\text { Turkey; 2012; } 161 \\
\text { pregnant women; } \\
\text { study group = 80; } \\
\text { control group =81 }\end{array}$ & $\begin{array}{l}\text { Individual care. Duration: during Visual Analog Scale } \\
\text { labor. Description: The study and Edinburgh Post- } \\
\text { group listened to self-selected } \\
\text { songs during labor. Postpartum } \\
\text { pain intensity, anxiety level and } \\
\text { satisfaction rates were measured } \\
\text { using the Visual Analog Scale, } \\
\text { and the postpartum depression } \\
\text { rate was assessed using the } \\
\text { Edinburgh Postpartum Depres- } \\
\text { sion Scale in postpartum days } \\
\text { one and eight }\end{array}$ \\
\hline
\end{tabular}

difference was observed be- maternal-fetal paramtween the two groups in terms eters and the need for of maternal hemodynamics and analgesics fetal heart rate after the intervention. Postpartum analgesic requirement decreased significantly in the study group

The study group had a lower level of postpartum pain and duced anxiety and this was statistically significant postpartum pain, inat all time intervals. A significant creased satisfaction difference was observed be- with the child's birth tween the two groups in terms and reduced the rate of satisfaction rate $(p<0.001)$ of early postpartum and the rate of postpartum depression. Music depression on days 1 and $8 \quad$ therapy can be clinically recommended as an analogous, safe, easy and pleasurable non-pharmacological method for postpartum well-being

Effects of music during To evaluate the multiple cesarean sec- effects of nursing tion delivery; Handan intervention using study group $=30$; et al. $(2018)^{17} \quad$ music therapy to re- control group $=30$ lieve anxiety levels in pregnant women with multiple cesarean sections
60 Individual care. Duration: during Structured questionthe c-section. Description: a list of naire and Visual Anatheir favorite songs was selected log Scale

to be played during the c-section.

They were reproduced at the desired volume of each patient throughout the surgery, using a stereo player. Physiological parameters and anxiety levels in the form of the questionnaire were recorded on the suture too. The data from the questionnaire were collected from women in the control group through interviews; their vital findings were recorded before and after anesthesia procedures, without intervention during the entire surgery

Coping with preopera- To assess the effects Israel; 2005; 60 pregtive anxiety in cesare- of an section: of - Individual care. Duration: 40 minutes before c-section. Description: a list of songs of their choice was selected. The study group listened to selected songs using a headset 40 minutes before the c-section.
Mood State Scale; Perceived Threat of surgery scale; vital signs before the 
in assisting parturient women, resstablishing the autonomy of women regarding labor and birth. ${ }^{35}$

As for the results found, we could not perform an in-depth analysis of the methodology, since some studies were inaccurate, omitted data, and/or presented vague information. In addition to the incomplete methodology, some of the studies selected do not inform if they were conducted by music therapists, and most of them were performed by other health professionals. As a result, these studies did not have a theoretical framework for music therapy and did not follow a validated protocol. Low methodological quality was a common finding among systematic reviews that examine music-based interventions, with variations between the number of interventions and the duration of each session, which can interfere with the results, limiting the benefits that the pregnant woman and her fetus could obtain; therefore, it is necessary to think about comprehensive interventions that cover the prenatal, delivery and postpartum periods. ${ }^{8}$

Carvalho $^{33}$ states that, in the practice of music therapy, music is not therapeutic, and is not used as an end in itself, but becomes a mediator of therapeutic individual or group relationship guided by a qualified and certified music therapist. It is important to remember that music therapy is included among the services provided by the Brazilian Unified Health System. In addition to maintaining its autonomy, it develops a practice consistent with the principles, seeking the necessary transformations, and without restricting its vision. The conviction regarding the contribution of studies on music therapy for the medical field brings another level of scientific knowledge necessary for the development of music therapy, thus answering existing questions. The need for the area to discuss some concepts is understood, contributing to clinical practice in different contexts. ${ }^{36}$

Another aspect to be observed was that most of the studies found were conducted outside Brazil (only three Brazilian publications were found), which suggests that further studies in this area should be carried out. Based on the results of previous studies, Brandalise ${ }^{37}$ states that there are few music therapists who publish articles and books reporting their findings and professional experiences, suggesting that there should be an incentive and preparation for the professional to engage in research.

\section{Conclusion}

From the results obtained, we can concluded that the performance of music therapy during the prenatal, delivery and postpartum periods can provide several benefits to the pregnant woman and the fetus, thus justifying its importance in this field. There is a demand in the job market for more professional music therapists, as well as for more studies on this subject performed by these professionals.

\section{Conflict of Interests}

The authors have no conflict of interests to declare.

\section{References}

1 Lima AA, Krey PSP, Fachini MF, Silva CR. Efeitos da musicoterapia sobre a ansiedade em parturientes. Rev Eletrônica Enferm Vale Paraíba.. 2014;1(06):83-93

2 Catafesta F, Zagonel IPS, Martins M, Venturi KK. A amamentação na transição puerperal: o desvelamento pelo método de pesquisacuidado. Esc Anna Nery. 2009;13(03):609-616. Doi: 10.1590/ S1414-81452009000300022

3 Wulff V, Hepp P, Fehm T, Schaal NK. Music in obstetrics: an intervention option to reduce tension, pain and stress. Geburtshilfe Frauenheilkd. 2017;77(09):967-975. Doi: 10.1055/s-0043-118414

4 García González J, Ventura Miranda MI, Manchon García F, et al. Effects of prenatal music stimulation on fetal cardiac state, newborn anthropometric measurements and vital signs of pregnant women: A randomized controlled trial. Complement Ther Clin Pract. 2017;27:61-67. Doi: 10.1016/j.ctcp.2017.03.004

5 Simavli S, Kaygusuz I, Gumus I, Usluogulları B, Yildirim M, Kafali H. Effect of music therapy during vaginal delivery on postpartum pain relief and mental health. J Affect Disord. 2014;156:194-199. Doi: $10.1016 /$ j.jad.2013.12.027

6 Arranz Betegón Á, García M, Parés S, et al. A program aimed at reducing anxiety in pregnant women diagnosed with a small-forgestational-age fetus: evaluative findings from a Spanish study. J Perinat Neonatal Nurs. 2017;31(03):225-235. Doi: 10.1097/ jpn.0000000000000270

7 Garcia-Gonzalez J, Ventura-Miranda MI, Requena-Mullor M, Parron-Carreño T, Alarcon-Rodriguez R. State-trait anxiety levels during pregnancy and foetal parameters following intervention with music therapy. J Affect Disord. 2018;232:17-22. Doi: 10.1016/j.jad.2018.02.008

8 van Willenswaard KC, Lynn F, McNeill J, et al. Music interventions to reduce stress and anxiety in pregnancy: a systematic review and meta-analysis. BMC Psychiatry. 2017;17(01):271. Doi: 10.1186/s12888-017-1432-x

9 Chuang $\mathrm{CH}$, Chen PC, Lee CS, Chen $\mathrm{CH}$, Tu YK, Wu SC. Music intervention for pain and anxiety management of the primiparous women during labour: A systematic review and meta-analysis.J Adv Nurs. 2019;75(04):723-733. Doi: 10.1111/jan.13871

10 Moher D, Liberati A, Tetzlaff J, Altman DGPRISMA Group. Preferred reporting items for systematic reviews and meta-analyses: the PRISMA statement. PLoS Med. 2009;6(07):e1000097. Doi: 10.1371/journal.pmed.1000097

11 Centre for Evidence-Based (CEBM) Oxford Centre for EvidenceBased Medicine: Levels of Evidence [Internet]. 2009 [cited 2018 Mar 5]. Available from: https://www.cebm.ox.ac.uk/resources/ levels-of-evidence/oxford-centre-for-evidence-based-medicinelevels-of-evidence-march-2009

12 da Costa Santos CM, de Mattos Pimenta CA, Nobre MRC. The PICO strategy for the research question construction and evidence search. Rev Lat Am Enfermagem. 2007;15(03):508-511. Doi: 10.1590/S0104-11692007000300023

13 Downs SH, Black N. The feasibility of creating a checklist for the assessment of the methodological quality both of randomised and non-randomised studies of health care interventions. J Epidemiol Community Health. 1998;52(06):377-384. Doi: 10.1136/jech.52.6.377

14 Kafali H, Derbent A, Keskin E, Simavli S, Gözdemir E. Effect of maternal anxiety and music on fetal movements and fetal heart rate patterns. J Matern Fetal Neonatal Med. 2011;24(03): 461-464. Doi: 10.3109/14767058.2010.501122

15 Toker E, Kömürcü N Effect of Turkish classical music on prenatal anxiety and satisfaction: A randomized controlled trial in pregnant women with pre-eclampsia. Complement Ther Med. 2017; 30:1-9. Doi: 10.1016/j.ctim.2016.11.005

16 Simavli S, Gumus I, Kaygusuz I, Yildirim M, Usluogullari B, Kafali H. Effect of music on labor pain relief, anxiety level and postpartum analgesic requirement: a randomized controlled clinical trial. Gynecol Obstet Invest. 2014;78(04):244-250. Doi: 10.1159/000365085 
17 Handan E, Sahiner NC, Bal MD, Dissiz M. Effects of music during multiple cesarean section delivery. J Coll Physicians Surg Pak. 2018;28(03):247-249. Doi: 10.29271/jcpsp.2018.03.247

18 Sen H, Yanarateş O, Sızlan A, Kılıç E, Ozkan S, Dağlı G The efficiency and duration of the analgesic effects of musical therapy on postoperative pain. Agri. 2010;22(04):145-150

19 Martins JT. Canto pré-natal: alquimias sonoras para gestantes. OuvirOUver.. 2017;13(02):630-643. Doi: 10.14393/OUV21-v13n2a2017-20

20 Tabarro CS, de Campos LB, Galli NO, Novo NF, Pereira VM. Efeito da música no trabalho de parto e no recém-nascido. Rev Esc Enferm USP. 2010;44(02):445-452. Doi: 10.1590/S0080-62342010000200029

21 Chang $\mathrm{HC}$, Yu CH, Chen SY, Chen $\mathrm{CH}$. The effects of music listening on psychosocial stress and maternal-fetal attachment during pregnancy. Complement Ther Med. 2015;23(04):509-515. Doi: 10.1016/j.ctim.2015.05.002

22 Liu YH, Lee CS, Yu CH, Chen CH. Effects of music listening on stress, anxiety, and sleep quality for sleep-disturbed pregnant women. Women Health. 2016;56(03):296-311. Doi: 10.1080/03630242. 2015.1088116

23 Liu YH, Chang MY, Chen CH. Effects of music therapy on labour pain and anxiety in Taiwanese first-time mothers. J Clin Nurs. 2010;19(78):1065-1072. Doi: 10.1111/j.1365-2702.2009.03028.x

24 García González J, Ventura Miranda MI, Requena Mullor M, Parron Carreño T, Alarcón Rodriguez R. Effects of prenatal music stimulation on state/trait anxiety in full-term pregnancy and its influence on childbirth: a randomized controlled trial.J Matern Fetal Neonatal Med. 2018;31(08):1058-1065. Doi: 10.1080/14767058.2017.1306511

25 Carolan M, Barry M, Gamble M, Turner K, Mascareñas O. The Limerick Lullaby project: an intervention to relieve prenatal stress. Midwifery. 2012;28(02):173-180. Doi: 10.1016/j.midw.2010.12.006

26 Nwebube C, Glover V, Stewart L. Prenatal listening to songs composed for pregnancy and symptoms of anxiety and depression: a pilot study. BMC Complement Altern Med. 2017;17(01): 256. Doi: 10.1186/s12906-017-1759-3

27 Yang M, Li L, Zhu H, et al. Music therapy to relieve anxiety in pregnant women on bedrest: a randomized, controlled trial. MCN Am J Matern Child Nurs. 2009;34(05):316-323. Doi: 10.1097/01. NMC.0000360425.52228.95
28 Bauer CL, Victorson D, Rosenbloom S, Barocas J, Silver RK. Alleviating distress during antepartum hospitalization: a randomized controlled trial of music and recreation therapy. J Womens Health (Larchmt). 2010;19(03):523-531. Doi: 10.10189/jwh.2008.1344

29 Kumar S, Sengupta A, Anand S. Novel method of feto-maternal monitoring using music therapy - A non-stress test. Int J Adv Res Comp Sci.. 2011;2(02):472-474. Doi: 10.26483/ijarcs.v2i2.427

30 Oh MO, Kim YJ, Baek CH, et al. [Effect of Music Intervention on Maternal Anxiety and Fetal Heart Rate Pattern During Non-Stress Test]. J Korean Acad Nurs. 2016;46(03):315-326. Doi: 10.4040/ jkan.2016.46.3.315 Korean.

31 Kushnir J, Friedman A, Ehrenfeld M, Kushnir T. Coping with preoperative anxiety in cesarean section: physiological, cognitive, and emotional effects of listening to favorite music. Birth. 2012;39(02):121-127. Doi: 10.1111/j.1523-536X.2012.00532.x

32 Taghinejad H, Delpisheh A, Suhrabi Z. Comparison between massage and music therapies to relieve the severity of labor pain. Womens Health (Lond). 2010;6(03):377-381. Doi: 10.2217/whe.10.15

33 Carvalho MES. Fundamentação de um programa de musicoterapia pré-natal. Int J Dev Educ Psychol.. 2018;1(01):109-116. Doi: 10.17060/ijodaep.2018.n1.v4.1047

34 Primo CC, Amorim MHC. Effects of relaxation on anxiety and salivary IgA levels in puerperae. Rev Lat Am Enfermagem. 2008;16 (01):36-41. Doi: 10.1590/S0104-11692008000100006

35 Gayeski ME, Brüggemann OM. Métodos não farmacológicos para alívio da dor no trabalho de parto: uma revisão sistemática. Texto Contexto Enferm. 2010;19(04):774-782. Doi: 10.1590/S010407072010000400022

36 Silva LC, Ferreira EABF, Cardozo EE. A música e a musicoterapia no contexto hospitalar: uma revisão integrativa de literatura. In: Anais do 14o Simpósio Brasileiro de Musicoterapia e 12o Encontro Nacional de Pesquisa em Musicoterapia; 2012 Out 11-14; Olinda, Brasil. Olinda: Associação de Musicoterapia do Nordeste; 2012:75-89

37 Brandalise A. A aplicação da música, realizada por musicoterapeutas e por outros profissionais da saúde, com pessoas em estados de baixo limiar de atenção: uma revisão sistemática. Rev Bras Musicoter.. 2014;14(17):69-85 